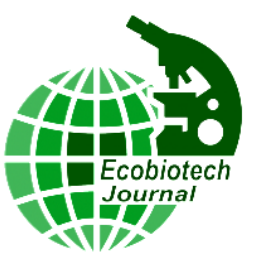

ЭКОО

УЧАСТИЕ АКТИВНЫХ ФОРМ КИСЛОРОДА И ФИТОГОРМОНОВ В ИНДУЦИРОВАННОЙ ЭНДОФИТНЫМИ МИКРООРГАНИЗМАМИ УСТОЙЧИВОСТИ РАСТЕНИЙ КАРТОФЕЛЯ К КОЛОРАДСКОМУ ЖУКУ

Сорокань А.В., Веселова С.В., Беньковская Г.В., Максимов И.В.

Институт биохимии и генетики Уфимского федерального исследовательского центра РАН, г. Уфа, Россия E-mail: fourtyanns@googlemail.com

Большой интерес представляет роль эндофитных бактерий в защите растений от фитофагов. Выявлено, что эндофитный штамм Bacillus subtilis 26Д стимулирует ранние защитные реакции растений картофеля на повреждение имаго колорадского жука, связанные с окислительным взрывом, а также способствует увеличению содержания фитогормонов - индолил-3-уксусной и абсцизовой кислот, участвующих в репарации и восстановлении роста. Присутствие эндофита во внутренних тканях растений имеет антифидантный эффект и способствует увеличению смертности вредителя после питания растениями.

Ключевые слова: Bacillus subtilis, абсцизовая кислота, активные формы кислорода, индолил-3уксусная кислота, колорадский жук, эндофиты

\section{PARTICIPATION OF REACTIVE OXYGEN SPECIES AND PHYTOGHORMONES \\ IN THE RESISTANCE OF POTATO PLANTS \\ TO COLORADO POTATO BEETLES INDUCED BY ENDOPHYTIC MICROORGANISMS}

\author{
Sorokan A.V., Veselova S.V., \\ Benkovskaya G.V., Maximov I.V. \\ Institute of Biochemistry and Genetics, \\ of the Ufa Federal Research Centre of RAS, Ufa, Russia \\ E-mail: fourtyanns@googlemail.com
}

The role of endophytic bacteria in protecting plants from phytophages is of great interest. It was revealed that the endophytic strain Bacillus subtilis 26D stimulates associated with the oxidative burst early protective reactions of potato plants to damage caused by adults of the Colorado potato beetle, and contributes to the increase of the content of phytohormones - indolyl-3-acetic acid and abscisic acid involved in repair and restoration of growth. The presence of endophyte in the internal tissues of plants has an antifidant effect and contributes to an increase of pest mortality after feeding plants.

Keywords: Bacillus subtilis, abscisic acid, reactive oxygen species, indolyl-3-acetic acid, Colorado potato beetle, endophytes

Поступила в редаки̧ию: 24.04.2020

DOI: $10.31163 / 2618-964 X-2020-3-2-143-149$

\title{
ВВЕДЕНИЕ
}

Современное высокоэффективное сельскохозяйственное производство невозможно без применения удобрений и средств защиты растений. До недавнего времени казалось, что для решения проблемы распространения колорадского жука достаточно рационального использования инсектицидов [Sukhoruchenko et al., 2008]. Однако, колорадский жук, как оказалось, обладает высокой эволюционной пластичностью, что позволяет ему не только мигрировать в регионы с различными климатическими условиями, но и обусловливает устойчивость к инсектицидам. Так, развитие резистентности к химическим инсектицидам обусловлено изменениями ограниченного числа генов насекомого, контролирующими некоторые метаболические пути, позволяющие сохранить жизнедеятельность при воздействии инсектицида [Ffrench-Constant, 2013]. Для замедления развития резистентности необходимо как можно более комплексное воздействие на организм жука, которое может быть достигнуто путем нарушения его связи с собственной микрофлорой, воздействием инсектотоксинов живых штаммов бактерий и защитными реакциями растений, 
индуцируемыми химическими иммуномодуляторами или штаммами стимулирующих рост растений микроорганизмов (СРРМ). Следует отметить, что некоторые СРРМ являются эндофитами, то есть обитают внутри тканей растений и защищены от воздействия внешних условий зоны рискованного земледелия и безопасны для насекомых, не являющихся фитофагами. Эндофитные симбионты растений могут вызвать определенные физиологические реакции, которые приводят к усилению резистентности растения к повреждению фитофагами. Это явление носит название индуцированной системной устойчивости - ISR (induced systemic resistance). Индуцируемая устойчивость не связана с прямой активацией биосинтеза защитных белков, но с феноменом, называемым защитным праймированием, которое тесно связано с ранними реакциями растений на стресс, такими как окислительный взрыв и реакция сверхчувствительности (СВЧ) [Martinez-Medina et al., 2016].

Реакция СВЧ, связанная с накоплением активных форм кислорода (АФК), широко используется в практике селекции при создании устойчивости к патогенам, а биохимические механизмы развития этого защитного механизма хорошо изучены и активно применяются при составлении селекционных программ. Роль АФК в защите растений от фитофагов не ясна. Поражения, подобные симптомам реакции сверхчувствительности, наблюдались у растений, пораженных некоторыми насекомыми [Chen, 2008]. Например, СВЧ-подобные поражения наблюдались у сортов ивы (Salix viminalis), устойчивых к галлице Dasineura marginemtorquens [Hoglund et al., 2005]. Эффектор слюнной железы Apolygus lucorum действует как глутатион-пероксидаза и подавляет генерацию АФК, индуцированную РАМР, такими как флагеллин, для ингибирования гибели клеток в результате СВЧ [Dong et al., 2020].

Ряд данных свидетельствуют о том, что накопление АФК в растениях, взаимодействующих с рост-стимулирующими бактериями, является ранней защитной реакцией против насекомых-фитофагов. Так, воздействие на корни Arabidopsis эндофитной бактерии B. velezensis YC7010 вызывает системную устойчивость к тле, предположительно, вследствие повышения генерации $\mathrm{H}_{2} \mathrm{O}_{2}$, гибели клеток и отложения каллозы в листьях [Rashid et al., 2017]. Du et al. [2015], напротив, показали, что ферменты, разрушающие АФК, такие как пероксидазы, участвуют в защитных реакциях против бурого кузнечика у устойчивых сортов риса.

Важно отметить, что повреждение фитофагами обладает долговременным негативным эффектом на продуктивность растений, уменьшает концентрацию сахара и крахмала в корнях и клубнях, отрастание корней и количество цветов у растений. Не смотря на большой объем исследований, посвященных роли салициловой (СК) и жасмоновой (ЖК) кислот в защитных реакциях от фитофагов, роль классических гормонов в процессах индуцированной устойчивости и репарации остается не выясненной. Так, показано, что экзогенная обработка индолил-3-уксусной кислотой (ИУК) растений Nicotiana attenuata после имитации повреждения Manduca sexta увеличивала диаметр розетки и число цветков. Эксперименты по применению и ингибированию транспорта ИУК показали, что ауксины могут действовать как дополнительные сигналы, которые регулируют возобновление роста растений после атаки вредителя [Machado et al., 2013]. Абсцизовая кислота (АБК) также является важным фактором реакции на высыхание, сопровождающее поедание растения фитофагом, представляется важным сохранение ее высокого уровня для репарации поврежденного растения [Schmelz et al., 2009]. Поэтому в данной работе были исследованы ранние реакции растений, содержащих в тканях эндофиты B. subtilis 26Д, на повреждение 
фитофагом, и более поздние, связанные с балансом фитогормонов в поврежденных растениях.

\section{МАТЕРИАЛЫ И МЕТОДЫ}

В работе использованы пробирочные стерильные растения картофеля сорта Ранняя роза, и перезимовавшие имаго колорадского жука, собранные с плантаций картофеля Бирского ОПХ (Башкортостан, Бирский район).

Растения картофеля инокулировали суспензией эндофитного штамма B. subtilis 26Д согласно методике, представленной в работе [Сорокань и др., 2018]. Часть опытных и контрольных растений скармливали имаго и личинкам колорадского жука и оценивали процент их смертности и активность питания (в мг сут. ${ }^{-1}$ особь $^{-1}$ ). В тестах с выбором имаго рассаживались по 1 особи в чашки Петри с растением, содержащим эндофиты B. subtilis 26Д, и со стерильным растением, интенсивность питания оценивали визуально, по количеству съеденных листьев.

Повреждение фитофагом проводили путем высаживания 1 имаго колорадского жука на 2-3 мин (масса съеденного растительного материала составляла не более 2-5 мг на 1 растение), после чего растительный материал фиксировался для исследования параметров редокс-метаболизма (через 1, 2, 3 часа) и содержания фитогормонов (через 1, 2, 3 суток). Ферментативная активность пероксидаз оценивалась по развитию окраски в реакционной смеси, содержащей перекись водорода и ортофенилендиамин [Sorokan et al., 2017]. Активность каталаз - по снижению содержания перекиси водорода, которая фиксировалась по окрашиванию молибдата аммония [Максимов, Сорокань и др., 2011]. Концентрация пероксида водорода определяться спектрофотометрически после окрашивания ксиленоловым оранжевым [Bindschedler et al., 2001]. Содержание фитогормонов (ИУК, АБК) было исследовано с помощью иммуноферментного аналаза, используя тест-системы для их определения с соответствующими стандартами и специфическими сыворотками.

\section{РЕЗУЛЬТАТЫ И ИХ ОСУЖДЕНИЕ}

При воздействии бактерии B. subtilis 26Д на организм насекомого, смертность личинок превышала контрольные показатели. Интересно, что смертность личинок под действием непосредственно суспензии B. subtilis 26Д, была ниже, чем в опыте с кормлением жуков растениями, содержащими клетки штамма в качестве эндофита. Если в тесте без выбора жуками была съедена примерно одинаковая масса растений, содержащих или не содержащих эндофиты, то в тестах с выбором из растения, содержащего клетки B. subtilis 26Д во внутренних тканях, и стерильного растения последние поедались более чем в 5 раз активнее (табл. 1).

Таблица 1. Антифидантный и инсектицидный эффект B. subtilis 26Д

\begin{tabular}{l|c|c}
\hline Показатель & Контроль (вода) & B. subtilis 26Д \\
\hline Смертность (суспензия), \% & $4,1 \pm 0,7$ & $18,1 \pm 1,5^{*}$ \\
Смертность (эндофит), \% & $6,7 \pm 0,5$ & $38,1 \pm 2,2^{*}$ \\
Повреждение растения за 60 мин, & $17,2 \pm 2,4$ & $3,3 \pm 0,3^{*}$ \\
тест с выбором, \% & & \\
Интенсивность питания, тест без & $83,8 \pm 9,4$ & $86,7 \pm 14,0$ \\
выбора, мг сут. особь $^{-1}$ &
\end{tabular}



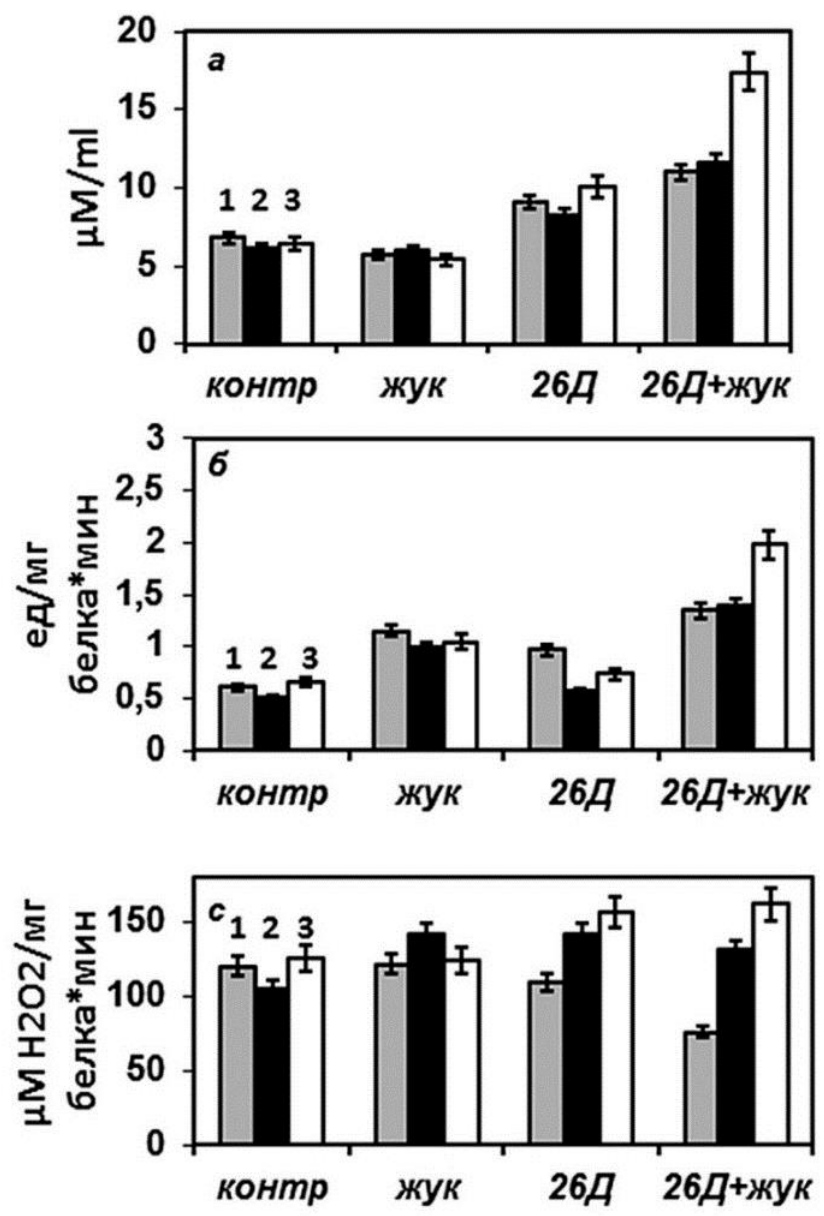

Рис. 1. Влияние B. subtilis 26Д на содержание перекиси водорода (а), активность пероксидаз (б) и каталазы (c) в растениях картофеля, поврежденных колорадским жуком. Цифрами отмечены 1, 2 и 3 часа после повреждения.
Бактерии B. subtilis 26Д индуцировали небольшое увеличение содержания перекиси водорода в растениях. После повреждения колорадским жуком в необработанных эндофитами растениях не наблюдалось развитие окислительного взрыва, а в растениях, содержащих эндофиты, происходило заметное накопление перекиси водорода, при этом увеличивалась активность пероксидаз. Активность каталаз в обработанных B. subtilis 26Д растениях картофеля была снижена через час после повреждения фитофагом, и ее активация наблюдалась через 3 часа и была связана, вероятно, с необходимостью удалить излишки АФК (рис. 1).

Было показано, что кратковременное повреждение растений картофеля колорадским жуком вызывало длительное снижение содержания ИУК (рис. 2), однако в растениях, содержащих клетки

эндофита B. subtilis 26Д, содержание как ИУК, так и АБК увеличивалось после контакта с фитофагом (рис. 2, 3), что, вероятно, способствовало сохранению темпов роста растений и развитию жасмонат-зависимых защитных реакций, эффективных против фитофагов [Erb et al., 2012]. Результаты Yan et al. [2017] свидетельствуют о том, что подавление транспорта ауксина является важным фактором в подавлении роста растений и удлинения корней под воздействием насекомых - фитофагов. Ими было показано, в корнях A. thaliana, листья которых подвергались нападению личинки бриллиантовой моли (Plutella xylostella L.) был нарушен транспорт ауксина и $\mathrm{H}^{+}$.

Важным представляется увеличение содержания АБК в обработанных суспензией $B$. subtilis 26Д растениях (рис. 3). В сигналлинге ЖК выделяются две различные антагонистические ветви транскрипционной регуляции: MYC-путь и ERF-путь. Повреждение грызущими фитофагами активирует MYC-зависимый путь [Verhage et al., 2011; Vos et al., 2013]. Эта ветвь контролируется основными факторами транскрипции helixloop-helix leucine zipper - MYC2, MYC3 и MYC4, приводящими к транскрипции сотен ЖКчувствительных генов, включая VSP1 и VSP2 [Anderson et al., 2004; Niu et al., 2011]. 


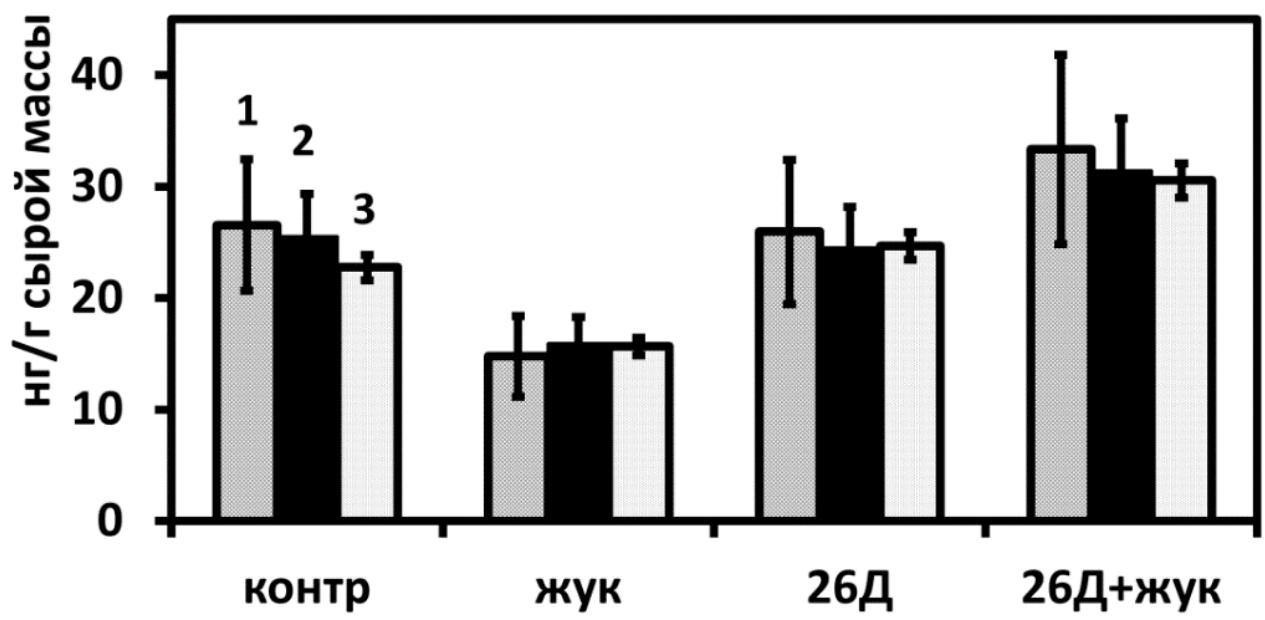

Рис. 2. Влияние B. subtilis 26Д на содержание ИУК в растениях картофеля, поврежденных колорадским жуком. Цифрами отмечены 1, 2 и 3 суток после повреждения.

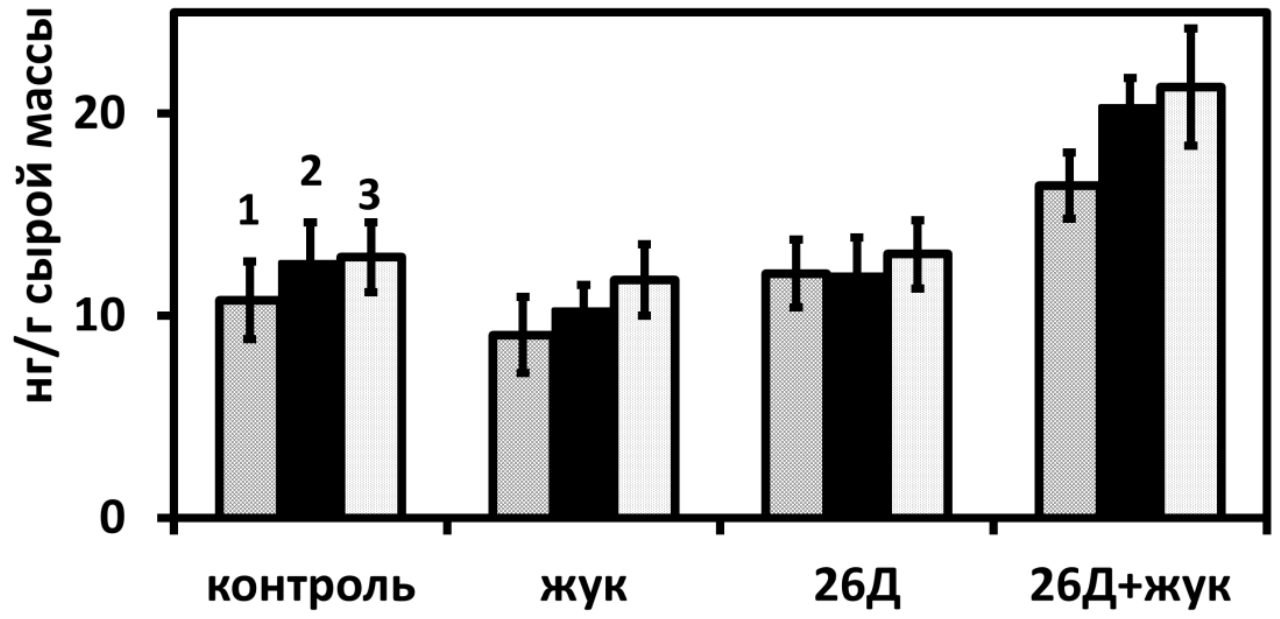

Рис. 3. Влияние B. subtilis 26Д на содержание АБК в растениях картофеля, поврежденных колорадским жуком. Цифрами отмечены 1, 2 и 3 суток после повреждения.

Исследования показали, что АБК играет роль в активации МҮС-ветви. Так, в АБКдефицитном мутанте aba2-1 экспрессия ЖК-чувствительного гена VSP1 была снижена при повреждении гусеницами Pieris rapae (малая капуста белянка) по сравнению с растениями дикого типа Col-0 [Vos et al., 2013]. В отличие от MYC-зависимого пути, индуцируемого фитофагами, ERF-ветвь активируется при заражении некротрофными патогенами. Было показано, что MYC-путь и ERF-путь жасмонатного сигнального пути могут антагонистически подавлять действие друг друга [Niu et al., 2011]. Экспрессию маркерного гена MYC-пути VSP2 и маркерного гена ERF-пути PDF1.2 исследовали в диком типе Arabidopsis Col-0 и мутантной по биосинтезу АБК линии aba2-1 при повреждении гусеницами P. rapae. Содержание транскриптов PDF1.2 в Col-0 было очень низким на фоне высокого содержания транскриптов VSP1. Мутанты aba2-1 демонстрируют низкую экспрессию VSP2 и высокую экспрессию PDF1.2 в течение 30 часов после повреждения [Vos et al., 2019].

Таким образом, эндофитные бактерии B. subtilis 26Д праймируют защитные реакции картофеля против колорадского жука, связанные с окислительным взрывом, а также, повидимому, МYС-путь сигналлинга ЖК, зависимый от АБК, что снижает поедание растений вредителем, а в дальнейшем - стимулирует процессы репарации, регулируемые ИУК. 
ФИНАНСОВАЯ ПОДДЕРЖКА

Работа выполнена при финансовой поддержке РНФ № 20-76-00003.

\section{СПИСОК ЛИТЕРАТУРЫ}

1. Anderson J.P., Badruzsaufari E., Schenk P.M., et al. Antagonistic interaction between abscisic acid and jasmonate-ethylene signaling pathways modulates defense gene expression and disease resistance in Arabidopsis // Plant Cell. 2004. V. 16. P. 3460-3479. https://doi.org/10.3389/fpls.2017.00587

2. Bindschedler L.V., Dewdney J., Blee K.A. Peroxidase-dependent apoplastic oxidative burst in Arabidopsis required for pathogen resistance // The Plant Journal. 2006. V. 47. P. 851863. https://doi.org/10.1111/j.1365-313X.2006.02837.x

3. Chen M.S., Zhao H.X., Zhu Y.C., et al. Analysis of transcripts and proteins expressed in the salivary glands of Hessian fly (Mayetiola destructor) larvae // Journal of Insect Physiology. 2008. V. 54. P. 1-16. http://dx.doi.org/10.1016/j.jinsphys.2007.07.007

4. Dong Y., Jing M., Shen D., et al. The mirid bug Apolygus lucorum deploys a glutathione peroxidase as a candidate effector to enhance plant susceptibility // J. Exp. Bot. 2020. pii: eraa015. https://doi.org/10.1093/jxb/eraa015

5. Du B., Wei Z., Wang Z., et al. Phloem-exudate proteome analysis of response to insect brown plant-hopper in rice // J. Plant Physiol. 2015. V. 183. P. 13-22. http://dx.doi.org/10.1016/j.jplph.2015.03.020

6. Ffrench-Constant R.H. The molecular genetics of insecticide resistance // Genetics. 2013. V. 194 (4). P. 807-815. https://doi.org/10.1534/genetics.112.141895

7. Hoglund S., Larrson S., Wingsle G. Both hypersensitive and non-hypersensitive responses are associated with resistance in Salix viminalis against the gall midge Dasineura marginemtorquens // J. Exp. Bot. 2005. V. 56. P. 3215-3222. http://dx.doi.org/10.1093/jxb/eri318

8. Machado R.A., Ferrieri A.P., Robert C.A., et al. Leaf-herbivore attack reduces carbon reserves and regrowth from the roots via jasmonate and auxin signaling // New Phytol. 2013. V. 200 (4). P. 1234-1246. https://doi.org/10.1111/nph.12438.

9. Martinez-Medina A., Flors V., Heil M., et al. Recognizing plant defense priming // Trends Plant Sci. 2016. V. 21. P. 818-822. https://doi.org/10.1016/j.tplants.2016.07.009

10. Niu Y., Figueroa P., Browse J. Characterization of JAZ-interacting bHLH transcription factors that regulate jasmonate responses in Arabidopsis // J. Exp. Bot. 2017. V. 62. P. 2143-2154. https://doi.org/10.1093/jxb/erq40

11. Rashid M.H., Khan A., Hossain M.T., Chung Y.R. Induction of systemic resistance against aphids by endophytic Bacillus velezensis YC7010 via expressing PHYTOALEXIN DEFICIENT4 in Arabidopsis // Front. Plant Sci. 2017. V. 8. P. 211-234. http://dx.doi.org/10.3389/fpls.2017.00211

12. Schmelz E.A., Engelberth J., Alborn H.T., et al. Phytohormone-based activity mapping of insect herbivore-produced elicitors // Proc. Natl. Acad. Sci. U.S.A. 2009. V. 106. P. 653657. https://doi.org/10.1073/pnas.0811861106

13. Sorokan A.V., Burhanova G.F., Maksimov I.V. Anionic peroxidase-mediated oxidative burst is required for jasmonic acid-dependent Solanum tuberosum L. defense against Phytophthora infestans (Mont) de Bary // Plant Pathology. 2018. V 67. P. 349-357. https://doi.org/10.1111/ppa.12743 
14. Sorokan A.V., Benkovskaya G.V., Blagova D.K., Maksimov I.V. Defense responses and changes in symbiotic gut microflora in the Colorado potato beetle Leptinotarsa decemlineata under the effect of endophytic bacteria from the genus Bacillus // J. Evol. Biochem. Phys. 2018. V. 54. P. 300-314. https://doi.org/10.1134/S0022093018040063

15. Sukhoruchenko G.I., Dolzhenko V.I. Problens of resistance development in arthropod pests of agricultural crops in Russia // EPPO Bulletin. 2008. V. 38 (1). P. 119-126. https://doi.org10.1111/j.1365-2338.2008.01194.x

16. Verhage A., Vlaardingerbroek I., Raaijmakers C., et al. Rewiring of the jasmonate signaling pathway in Arabidopsis during insect herbivory // Frontiers in Plant Science. 2011. V. 2. 47. https://doi.org/10.3389/fpls.2011.00047

17. Vos I.A., Verhage A., Watt L.G., et al. Abscisic acid is essential for rewiring of jasmonic acid-dependent defenses during herbivory // BioRxiv. 2019. https://doi.org/10.1101/747345

18. Yan S., Jiao C., McLamore E.S., et al. Insect herbivory of leaves affects the auxin flux along root apices in Arabidopsis thaliana // J. Plant Growth Regul. 2017. V. 36. P. 846-854. https://doi.org/10.1007/s00344-017-9688-4 